\title{
EMBOLECTOMY IN THE LIMB ARTERIES
}

\author{
David J. TibBS, M.C., M.S.(Lond.), F.R.C.S. \\ Department of Surgery, Royal Victoria Infirmary, Newcastle upon Tyne
}

Embolism to the limb arteries is usually a condition which is best treated by conservative means but there are a number of cases in which failure to reopen the occluded circulation may lead to loss of the limb and indeed loss of life. The increased confidence with which surgeons operate upon arteries and the facility with which extensive lengths of arteries may be cleared of clot have brought about a decided improvement in the prospect of saving the limb and preserving good function; however, the overall mortality of the general condition giving rise to embolism remains high and it might be said that surgical progress has not been matched by medical progress in this field. In this paper it is proposed to outline our policy towards major arterial embolism in the vessels to the limbs and to present some indication of the results which this policy may bring.

\section{The Origin and Significance of Arterial Emboli}

In this article we are not concerned with lesser emboli but with those of sufficient size to occlude the main arterial supply to a limb or, when the aorta is involved, to both lower limbs. In Tables I and 2, experience with 27 such cases treated on the Professorial Surgical Unit of the Royal Victoria Infirmary is summarized. Mitral stenosis with auricular fibrillation is the commonest single cause, but the detachment of a mural thrombus following a coronary thrombosis is almost as common. Occasionally a massive arterial embolus appears without obvious source, although in these patients it usually transpires that the embolus took origin in the heart as a result of a damaged myocardium. There are, of course, other possible origins for an embolus but these do not usually create a need for surgical interference. Enough has been said already to make clear one point which is of the greatest importance in the management of major arterial limb embolism; most of the patients suffer from some form of heart disease and the embolus is a mere, although perhaps dangerous, complication of what may be a very serious cardiac state. For this reason, surgery should only be used in arterial embolism to save a limb which would otherwise inevitably become gangrenous and create an added threat to the patient's life; incidentally, with an embolus of this magnitude the patient's general condition will often improve after the circulation has been reopened.

Particularly dangerous is the state of the patient who has developed massive embolism after a coronary thrombosis. Table I shows that six out of ten of our patients showing this combination died from heart failure even though in most a satisfactory circulatory equilibrium had been reached after the operation. In this class of patient surgery must never be employed without the most pressing indications.

\section{Symptoms and Signs of Severe, Extensive Ischaemia}

The patient can usually tell to the minute when the embolus arrived; this and the absence of preceding intermittent claudication help in the distinction between embolism and local thrombosis within a diseased artery. The initial pain soon wears off and is replaced by numbness. Examination shows pallor or mottling of the skin, the pulses are absent below the embolus and the limb will gradually become cold. These changes, however, do not tell us whether the limb has sufficient circulation left to survive. A dangerously severe ischaemia gives rise to cutaneous anaesthesia of a ' stocking and glove' distribution and this is a most valuable prognostic guide. A limb showing extensive anaesthesia persisting for more than two or three hours, in spite of conservative treatment, is in very real danger. Another sign may be added to this: the muscles involved may become swollen, tender and contracted and stretching them causes severe pain. This state is characteristic of muscle which has lost its blood supply and is analogous to rigor mortis. Its appearance, although perilously late, does not necessarily indicate a hopeless situation (Fig. I); it is a sign that massive muscle death is imminent or has actually occurred; the state of the 


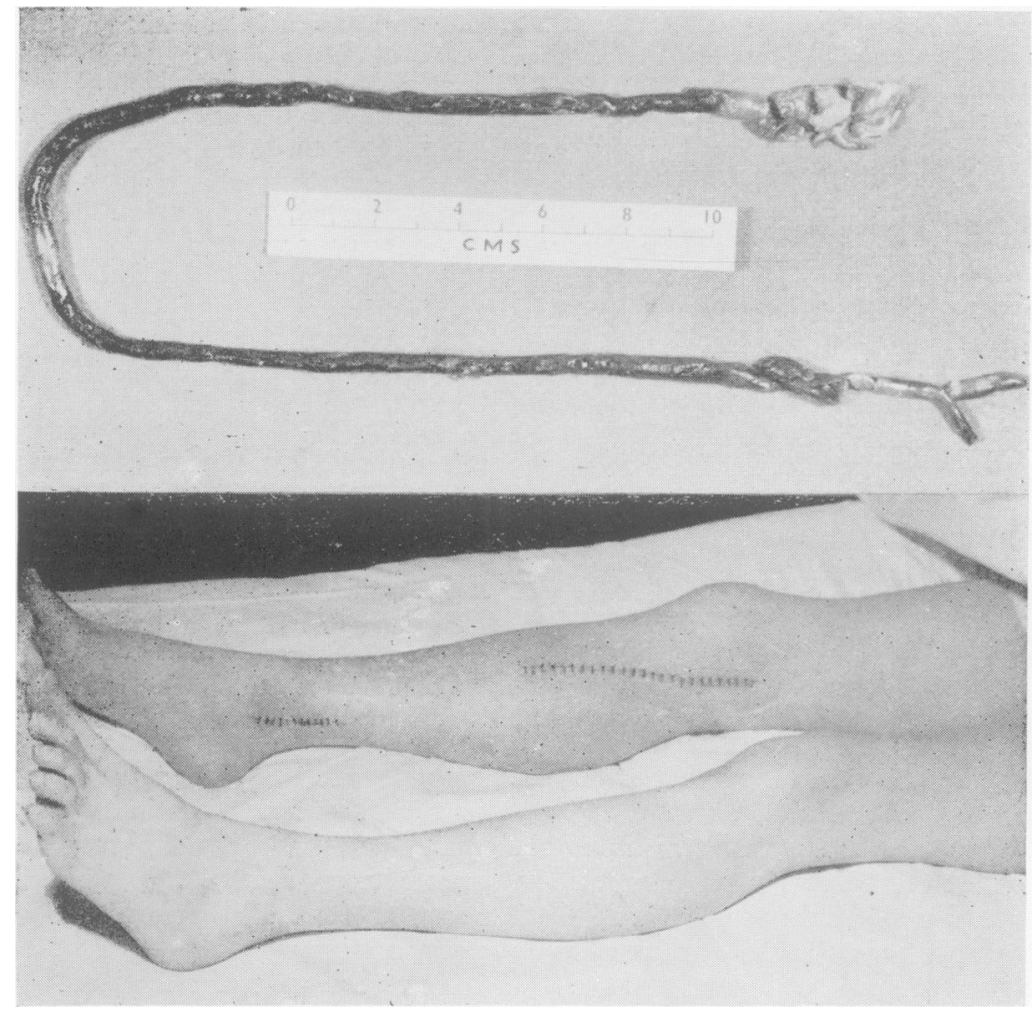

Fig. I.-Photograph of clot removed by retrograde flushing; this formed a cast of the arterial tree from the common femoral artery down to the division of the popliteal artery; the tails corresponding to the tibial arteries and the profunda femoris can be seen. Embolism had occurred 24 hours before embolectomy; the limb, prior to operation, had shown anaesthesia up to the knee and the calf muscles were swollen and contracted. The appearances of the limb on the day following operation are also shown; swelling and contracture of the calf muscles is still present and the skin shows a blotchy erythema. This limb recovered almost completely with virtual disappearance of the muscle changes although the tips of two small toes became gangrenous. The patient had had a series of coronary thromboses and he died of heart failure six weeks after embolectomy.

corresponding hand or foot is usually equally critical.

The decision for surgery can usually be based on the index of severity of ischaemia provided by the extent of anaesthesia and the presence of muscle contracture.

\section{The Time Factor}

If a tourniquet is applied to a limb, anaesthesia develops within an hour and ischaemic contracture of the muscle after about six to eight hours. Restoration of the circulation after this period is unlikely to save the limb and there is a very real risk of ' touniquet shock' or other manifestations such as anuria. The march of events with arterial occlusion by an embolus is not usually so rapid or relentless as this, however, because the ischaemia is seldom absolute and the veins remain open (although extensive venous thrombosis may super- 윽 vene). The collateral circulation even in severe

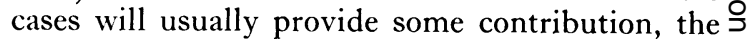
value of which can be assessed fairly accurately by $\frac{T}{0}$ noting the severity of the signs of ischaemia in the limb and especially the extent of the sensory loss. N Initially the collateral circulation may be impeded by spasm but, after an hour or two, this may wear off and a corresponding improvement occur; $\omega$ improvement may also occur through actual shifting of the embolus. In this respect the lapse of time may prove an advantage but, on the other $\mathbb{D}$ hand, particularly when collaterals are poor, and the flow they supply is meagre, consecutive thrombosis in the stagnant blood within the $\overrightarrow{\mathbb{D}}$ artery often occurs so that the situation is further $\frac{\stackrel{\mathrm{P}}{\mathbb{D}}}{\sigma}$ 
TABLE I

Axalysis of 27 Cases of Major Arterial Embolism AfFecting THE Limbs and TREATED BY EMBolectomy (Professorial Surgical Unit, Royal Victoria Infirmary, 1955-59)

Age 30 years to 84 years-average 60 years

\begin{tabular}{|c|c|c|}
\hline Site of Embolus & & $\begin{array}{c}\text { No. of } \\
\text { Cases }\end{array}$ \\
\hline Aortic bifurcation $\quad \ldots \quad \ldots \quad \ldots$ & . & 9 \\
\hline Common iliac arteries $\left\{\begin{array}{l}\text { unilaterally } \ldots \\
\text { bilaterally } \ldots\end{array}\right.$ & $\begin{array}{l}\cdots \\
\ldots\end{array}$ & $\begin{array}{l}9 \\
2\end{array}$ \\
\hline Common femoral arteries $\left\{\begin{array}{l}\text { unilaterally } \\
\text { bilaterally }\end{array}\right.$ & $\begin{array}{l}\cdots \\
\ldots\end{array}$ & $\begin{array}{l}4 \\
2\end{array}$ \\
\hline Upper brachial artery .. $\ldots$ & . & $\mathbf{I}$ \\
\hline
\end{tabular}

In 13 patients two limbs were involved. In most limbs consecutive thrombus was present.

\begin{tabular}{|c|c|c|}
\hline $\begin{array}{l}\text { Origin of } \\
\text { Embolus }\end{array}$ & Cardiac State & $\begin{array}{l}\text { No. of } \\
\text { Cases }\end{array}$ \\
\hline $\begin{array}{l}\text { The heart }\{ \\
\text { Lncertain }\end{array}$ & $\begin{array}{l}\text { Mitral stenosis and fibrillation } \\
\text { Coronary thrombosis .. } \\
\text { Fibrillation (origin uncertain). }\end{array}$ & $\begin{array}{r}14 \\
10 \\
1 \\
2 \\
\end{array}$ \\
\hline
\end{tabular}

\begin{tabular}{|c|c|}
\hline Technique of Embolectomy Employed & $\begin{array}{l}\text { No. of } \\
\text { Cases }\end{array}$ \\
\hline $\begin{array}{l}\text { Local extraction of embolus and clot } \\
\text { Local extraction with milking } \\
\text { Local extraction combined with retrograde }\end{array}$ & $\begin{array}{r}4 \\
12\end{array}$ \\
\hline $\begin{array}{llllll}\text { flushing } & \ldots & \ldots & \ldots & \ldots & \ldots \\
\end{array}$ & I I \\
\hline
\end{tabular}

Deaths whilst still in hospital-total 12 patients. In

6 cases two limbs were originally involved.

Average survival: 12 days post-operatively.

\begin{tabular}{|c|c|}
\hline Cause of death & $\begin{array}{l}\text { No. of } \\
\text { Cases }\end{array}$ \\
\hline 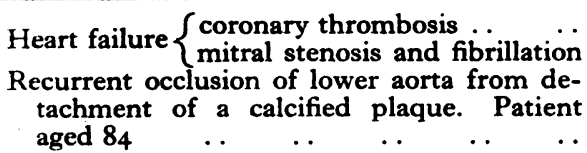 & $\begin{array}{l}6 \\
5\end{array}$ \\
\hline
\end{tabular}

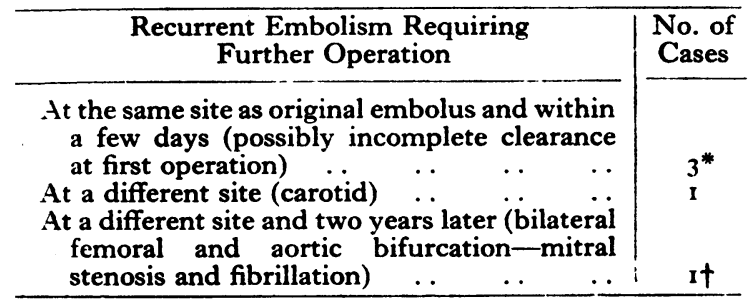

* Two patients left hospital alive and with both limbs satisfactory.

† Excellent result to both operations.

Many episodes of minor embolism, not requiring operation, were seen at all stages of recovery. aggravated. Fortunately this unfavourable aspect of the time factor can be minimized by use of heparin without prejudice to surgical treatment.

It used to be thought that surgical removal of an embolus was unlikely to give a patent artery if the procedure were not undertaken within a few hours of onset. This is not true because clot can be removed days or even weeks later to give an artery which will remain patent provided its peripheral outflow is not impeded by inadequate clearance of clot. ${ }^{6}$ (In nearly, every case summarized in Table 2 the main artery remained open and pulsatile after embolectomy and any residual ischaemic symptoms arose from occlusion of the lesser arteries.) It is true, however, that within 24 hours the consecutive thrombus is supple and has relatively good resistance to fragmentation so that it may be withdrawn quité easily; later the clot becomes more firm, brittle and slightly adherent so that technically it is more difficult to withdraw it by any means from the side branches. In this respect the sooner embolectomy is undertaken, the more complete will be success in restoring circulation to that limb; late embolectomy may well be successful but will involve a more complex and extensive operation.

It is permissible to spend an hour or two in assessment of a limb and in making sure that, under favourable conditions, spontaneous improvement is not going to occur. If the persistence of anaesthesia makes it clear that surgery is obligatory in order to save the limb, then further time should not be lost.

\section{Contraindications to Surgery}

The ischaemia is not of sufficient severity. Colour, warmth and sensation or the presence of a popliteal pulse or brachial pulse at the elbow may all indicate that the limb will survive. It is seldom justifiable to undertake emergency surgery for embolism merely to avoid claudication. This condition can be relieved at a later stage if necessary.

Ischaemia has been present for too long. Staining of the skin over any sizable area, a line of demarcation, extensive calf muscle contracture, the knowledge that the condition developed 12 or more hours previously are all factors which may well add up to contraindicate embolectomy because extensive tissue death has already occurred. This is not an easy decision; at least five patients in our series were operated upon with success when the limbs were apparently irrecoverable. The limb after operation, under these circumstances, becomes oedematous; skin erythema and blistering may develop and possibly small gangrenous patches, especially on the toes, but in spite of this, in favourable cases, slow recovery of 
TABLE 2.-OUtcome to Limb

Period of Ischaemia Prior to Embolectomy and the Eventual function Obtained in the Limbs of I5 Patients (2i Limbs at Risk) Surviving to Leave Hospital

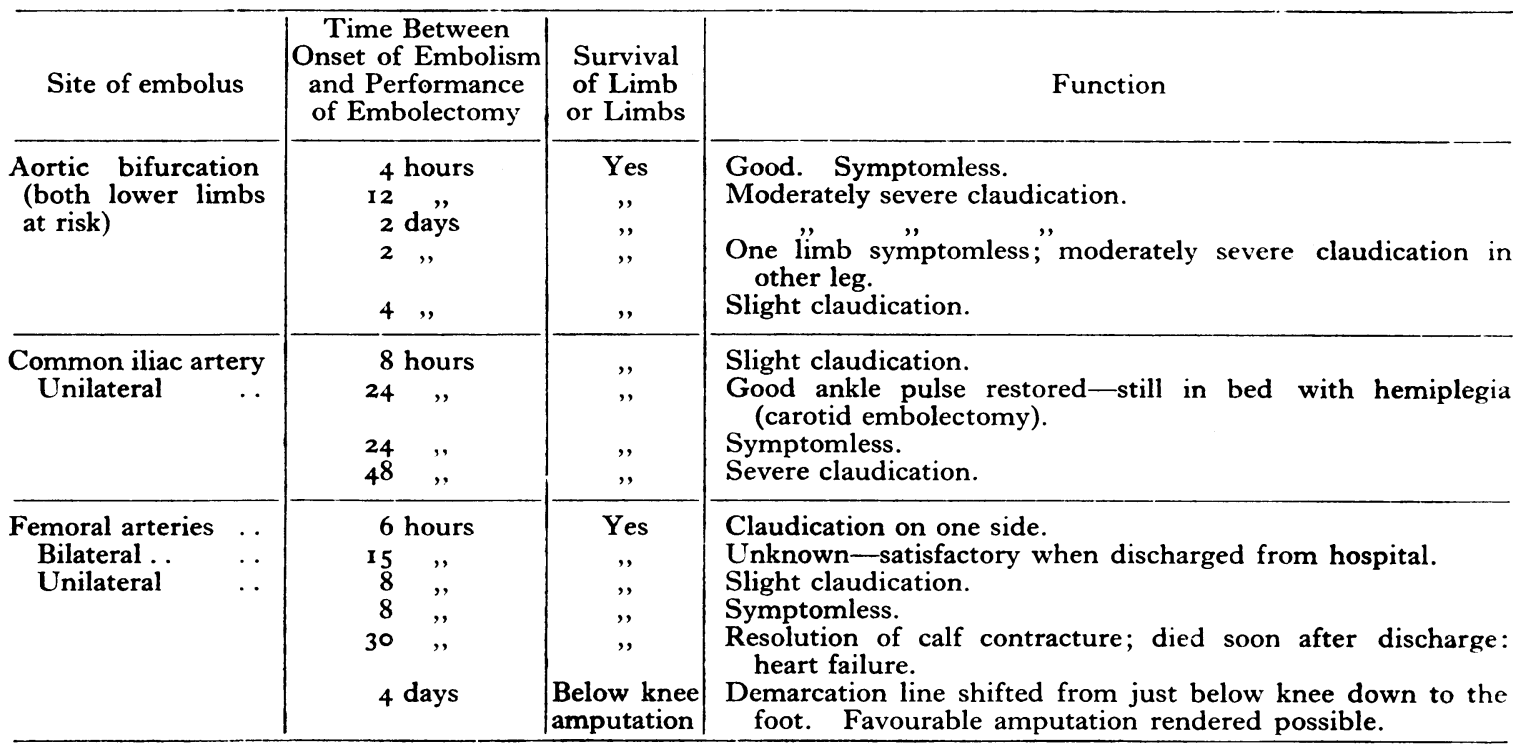

Summary: 20 useful limbs; $x$ below knee amputation.

State of the Limbs in i2 Patients Dying in Hospital

\begin{tabular}{c|c|c|}
\hline Limb state & $\begin{array}{c}\text { No. of } \\
\text { Patients }\end{array}$ & Comment \\
\cline { 2 - 3 } $\begin{array}{c}\text { Both limbs in satisfac- } \\
\text { tory state }\end{array}$ & $\begin{array}{c}8 \text { (15 limbs } \\
\text { at risk) }\end{array}$ & $\begin{array}{c}\text { At least an adequate circulation was returned to these limbs; function could } \\
\text { not be assessed as patients were confined to bed until time of death. }\end{array}$ \\
\hline Gangrene of one limb.. & 4 & $\begin{array}{l}\text { Factors in these four cases were: } \\
\text { Case }(a): \text { Embolectomy too late and patient too ill for adequate operation. } \\
\text { Case }(b): \text { Recurrent ', embolism-? inadequate original clearance. } \\
\text { Case }(c): \text { Recurrent' embolism-? inadequate original clearance. } \\
\text { Case }(d) \text { : Unrelieved occlusion of aorta. }\end{array}$ \\
\hline
\end{tabular}

Note.-Gangrene did not appear to contribute to the patient's death-all patients developing gangrene were very ill for other reasons and therefore further operation was prevented when renewed ischaemia became evident.

sensation will occur and eventually a useful limb is obtained.

Reopening the circulation in border-line cases is not without some risk, because there is always the theoretical danger of 'tourniquet shock' or a type of 'crush syndrome.' A massive septic necrosis of muscle may develop due to the fact that reopening the circulation has converted a dry infarction of muscle into a wet gangrene. Fortunately, however, this sort of event is rare and we believe it is permissible in cases of doubtful viability to give embolectomy a trial.

The cardiac state. The operations of embolectomy under skilled general anaesthesia do not appear to offer any great immediate risk even in patients with quite severe cardiac disease. However, the embolus may be but one manifestation in a dying patient and an operation would be an ill-judged gesture. Our policy is to accept the 읙 immediate risk of surgery if the cardiologist believes that the cardiac state is not in itself $\frac{}{2}$ likely to prove fatal and providing the alternative $\frac{D}{O}$ is a gangrenous limb.

\section{The Initial Management Within Hospital}

Blood is taken for cross-matching; 10,000 units of heparin are given intravenously. The area of $\omega$ cutaneous anaesthesia in the affected $\operatorname{limb}$ is accurately mapped out and a search made for $\stackrel{0}{\subset}$ muscle contracture. A careful assessment of the $\stackrel{\mathbb{D}}{\mathbb{D}}$ cardiac state is made and the patient sedated with $\frac{1}{3}$ gr. of omnopon.

The ischaemic limb is kept cool and the rest $\frac{0}{\mathbb{D}}$ of the patient warmed in order to relax sympa- 

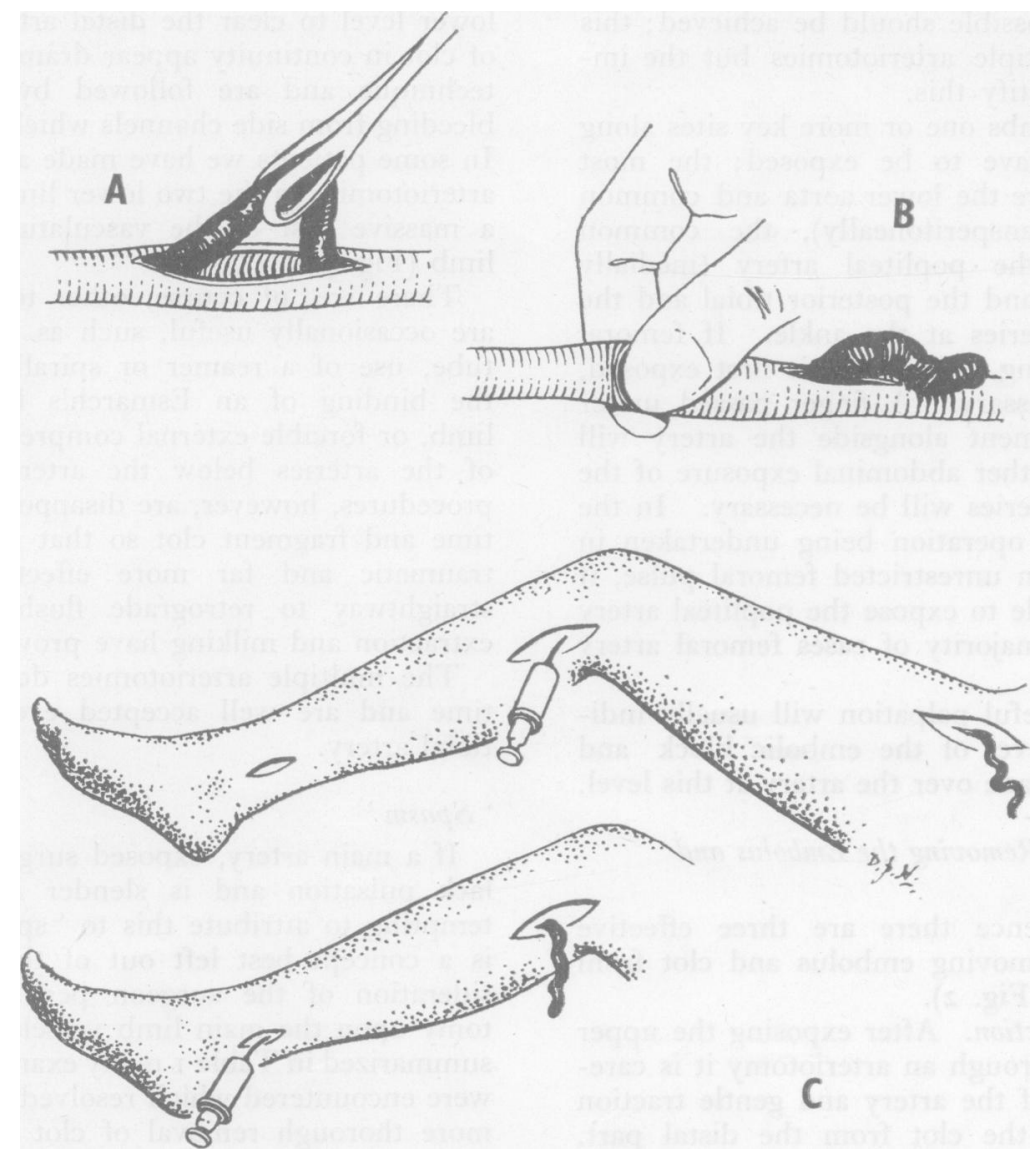

Fig. 2.- The techniques for removal of embolus and consecutive clot. $A$, Local extraction. Before any clamps are applied the clot is delivered through an arteriotomy and gently drawn upon. If the clot is recent, considerable lengths of consecutive thrombus may be extracted. $B$, Milking clot towards the arteriotomy. This can be very effective in exposed portions of arteries. $C$, Retrograde flushing. A cannula is introduced in order to flush forcibly the portion of the artery above it. Very extensive consecutive thrombus can be removed in this fashion with minimal interference to the arteries.

thetic tone; vaso-dilator drugs may be employed but we do not advise any intra-arterial injections. The limb should be kept in a slightly dependent position; any elevation will further diminish the available blood. If complete anaesthesia is present up to the knee or any muscle contracture is present, operation should be undertaken without delay; in other cases the limb is watched for an hour or two. If complete sensory loss persists above the ankle without any significant regression, then embolectomy should be undertaken. If, however, anaesthesia has shown steady regression so that only the forefoot is involved, then it is probably safe to continue waiting and observing because the collateral circulation may be adequate. In cases such as this, the decision for or against surgery may be difficult and in the lower limb a useful deciding factor is the presence or not of a popliteal pulse-if a pulse is present the foot will probably survive and embolectomy is unnecessary; conversely, absence of this pulse, or more specifically of the femoral pulse, indicates that embolectomy is best undertaken. In our experience all aortic and most cases of iliac and femoral artery embolism require surgery if the limb is to be preserved; this accords closely with the findings and recommendations of Jacobs. 4

\section{The Operation}

The modern conception of embolectomy is that not only should the embolus itself be removed, but also as near complete clearance of consecutive 
thrombus as is possible should be achieved; this may involve multiple arteriotomies but the improved results justify this.

In the lower limbs one or more key sites along the artery will have to be exposed; the most favourable sites are the lower aorta and common iliac arteries (transperitoneally), the common femoral artery, the popliteal artery (medially below the knee), and the posterior tibial and the dorsalis pedis arteries at the ankle. If femoral pulsation is missing, this artery is first exposed, bilaterally if necessary. A finger passed under the inguinal ligament alongside the artery will soon indicate whether abdominal exposure of the aorta and iliac arteries will be necessary. In the unusual event of operation being undertaken in the presence of an unrestricted femoral pulse, it may be permissible to expose the popliteal artery first, but in the majority of cases femoral artery exposure is wise.

In the arm careful palpation will usually indicate the upper level of the embolic block and incision will be made over the artery at this level.

\section{The Technique of Removing the Embolus and Propagated Clot}

In our experience there are three effective techniques for removing embolus and clot from within an artery (Fig. 2).

(a) Local Extraction. After exposing the upper end of the clot through an arteriotomy it is carefully teased out of the artery and gentle traction exerted to draw the clot from the distal part. This manoeuvre can be surprisingly successful and may draw up an extensive cast of the main arteries. More usually the clot breaks so that the procedure is limited in its scope; naturally no arterial clamps should be applied until it has been attempted for fear of prematurely breaking the clot.

(b) Milking. If it is assessed that the clot is not extensive, the artery may be milked firmly between the fingers. This is very effective for clearing the portion of artery actually accessible in the wound, but beyond this there is a tendency to break the clot and leave portions behind so that it is of limited value.

(c) Retrograde Flushing.1, 2, 5, 7 This technique is of outstanding merit and should be employed without hesitation if it appears that removal of clot is incomplete by the preceding method. This technique is at its best if the clot has not been broken up by previous manoeuvres. The artery is exposed and cannulated at the next ' favourable site' more distally; heparinized saline is then forcibly pumped up the artery to eject the clot within it through the upper arteriotomy. If necessary, the procedure is repeated from a still lower level to clear the distal artery. Long coils of clot in continuity appear dramatically with this technique and are followed by vigorous back bleeding from side channels which are opened up. In some patients we have made as many as seven arteriotomies in the two lower limbs and removed a massive cast of the vasculature of the lower limb (Fig. 3).

There are, of course, other techniques which are occasionally useful, such as use of a suction tube, use of a reamer or spirally wound wires, the binding of an Esmarch's bandage up the limb, or forcible external compression on the line of the arteries below the arteriotomy. These procedures, however, are disappointing; they lose time and fragment clot so that usually it is less traumatic and far more effective to proceed straightway to retrograde flushing when local extraction and milking have proved insufficient.

The multiple arteriotomies do not take much time and are well accepted even by the posttibial artery.

\section{'Spasm'}

If a main artery, exposed surgically, is seen to lack pulsation and is slender in calibre, it is tempting to attribute this to 'spasm.' 'Spasm is a concept best left out of the practical con sideration of the surgeon performing emboleco tomy upon the main limb vessels. ${ }^{3}$ In the series. summarized in Table I many examples of ' spasm ? were encountered which resolved completely with more thorough removal of clot from within the artery above the area of 'spasm.' Under these circumstances, 'spasm' is due to lack of pressure and interruption of the pulse by clot occluding the artery at a higher level. If longitudinal pulsation is seen, this signifies an artery filled with clot a short distance below patent artery; the pulsation of the artery above is being transmitted in a plunger-like fashion by the clot-filled artery.

\section{Criteria of Success}

A pulsatile flow should be obtained from above. Vigorous back bleeding from the distal artery is a good indication that there has been reopening of a useful part of the arterial tree. The arteriotomy may then be closed and the flow restarted and the distal pulses palpated. At least the popliteal pulse should have returned; if this not palpable, then this artery is exposed and retrograde flushing employed, even if this means reopening the upper arteriotomy.

A successful retrograde flush of course indicates that at least the main channel is patent. Restoration of wrist or ankle pulses is most reassuring, but their presence is not essential for recovery; if sufficient reopening of the circulation has been 


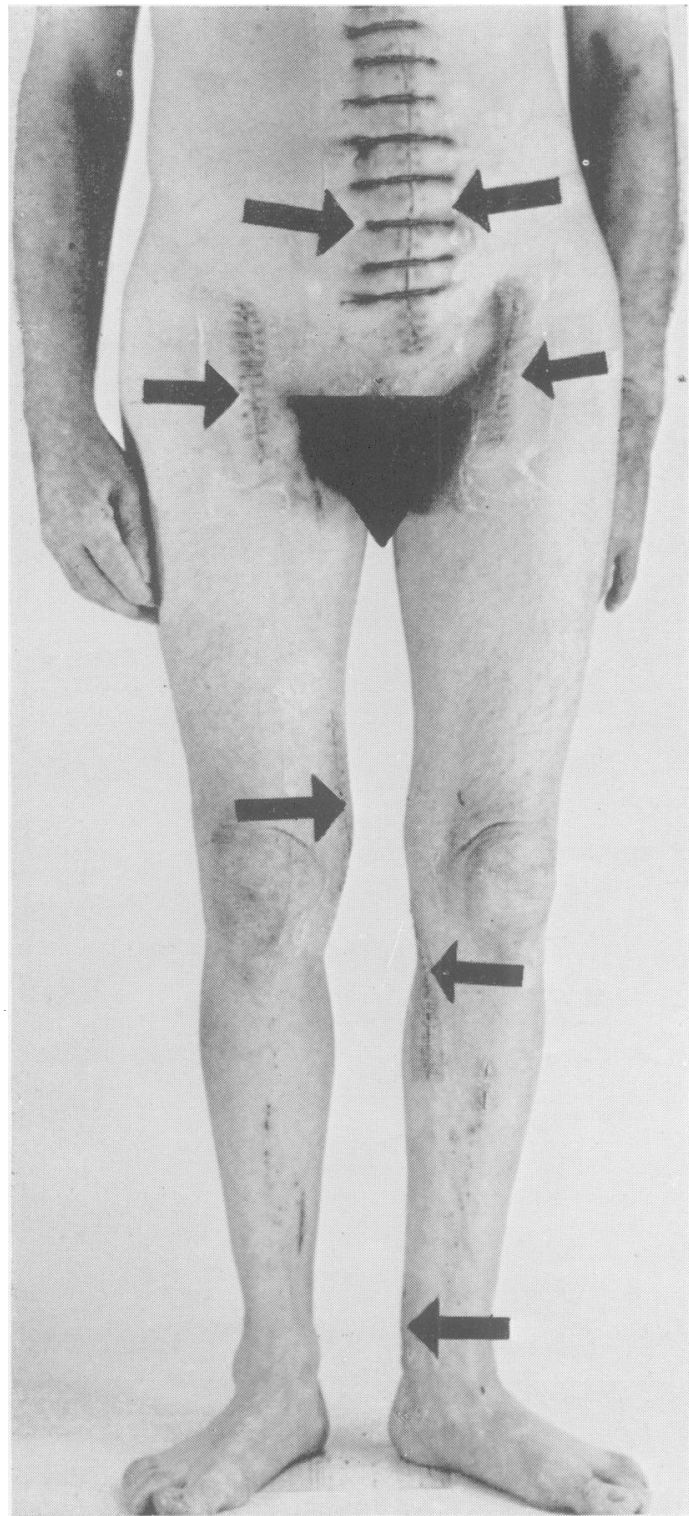

FIG. 3.-This patient's lower limbs were thought to be beyond recovery as a result of a two-day-old saddle embolus. The main arteries of both limbs were completely occluded by thrombus extending from aorta to the tibial arteries. Retrograde flushing was employed through arteriotomies at the sites indicated. The left limb regained excellent return of function, but the right limb after recovery showed severe claudication due to less adequate clearance. This patient was well six months later.

accomplished, the pallor in the extremity will be replaced by return of at least a tinge of colour and the veins will become well filled.

The surgeon undertaking embolectomy must be prepared to clear the length of the artery, with some speed, through multiple incisions. Blood loss is not usually very great and the patients seem little disturbed by this procedure. If clearance has been thorough, anticoagulants are not necessary in the immediate post-operative phase, indeed they add materially to the risks. It is wise, however, to put the patient on long-term anticoagulants after the first week in order to minimize further embolic episodes. The patient is encouraged in active limb movements and, whenever possible, ambulation is commenced at about one week after the operation. In the patients with mitral stenosis, valvotomy should be given careful consideration as a means for preventing further embolism.

\section{Immediate Recurrence of Embolism}

A further ' embolism' occurring within a few days to the same site as the original embolus is possibly due to incomplete removal of clot at the original operation. If the limb is once more in jeopardy, the operation must be repeated on the same indications as the original procedure. There is no special difficulty in this re-operation and in our small series this was undertaken, with success, on three occasions.

A true recurrent embolism quite often does occur to other parts of the body and must be treated on its merits even if this means further surgery; more usually it is a minor episode that will require medical treatment alone. The following case history is a good example of the precarious state of this class of patient and the disappointments that may follow an outstanding initial success.

The patient, aged 60 , was admitted with a 24-hour-old common iliac embolus following coronary infarction. Although there was extensive clotting below the embolus, it was successfully dealt with by retrograde flushing through multiple arteriotomies. Fourteen days later, just before his discharge from hospital, he developed pain in the left eye, mental confusion and a right hemiplegia. Temporal artery pulsation was absent on the left side. He was promptly taken to theatre where, under local anaesthetic, an embolus was removed from the bifurcation of the left common carotid and a long consecutive clot extracted from the occluded internal carotid artery; pulsatile flow was restored within an hour of onset but, although there was an immediate return in mental responsiveness, the hemiplegia persisted.

\section{Discussion}

Our experience with embolectomy is largely confined to the lower limbs and two features of interest emerge. Firstly, that most lower limbs 
with major embolus can be saved by adequate surgery provided the patient's cardiac state is compatible with continued life; secondly, that the lapse of several days with severe ischaemia, the presence of extensive ischaemic muscle contracture or even an early demarcation line do not necessarily preclude salvage of a useful limb. In this respect, the more extensive operations recently undertaken to achieve reopening of the arterial tree have been fully justified.

It is necessary to consider to what extent the high survival rate of the limbs in our series (Table 2) has been achieved at the cost of increased mortality. It is important to bear in mind that only the obviously moribund or the hopelessly late cases with well developed gangrene were refused embolectomy and many of our patients had slender chances of recovery by any means; our surgical mortality rate could certainly have been more favourable if rigid selection had been excrcised. Table I shows that most of the patients who succumbed lived for sufficient time after the embolectomy to suggest that surgery in itself was an unimportant factor. There were two patients, however, in whom surgery apparently hastened death.

One patient with mitral stenosis and bilateral common iliac emboli died a few hours after operation and, at autopsy, it was found that she had developed a large retroperitoneal haematoma. This case occurred early in the series and at that time heparin was given post-operatively. Sudden blood loss is clearly most undesirable in the cardiac invalid and this is the reason why heparin is best avoided in the immediate post-operative phase.

The second patient (recent coronary thrombosis and aortic embolus) died on the operation table, but if she died during an uneventful operation, then she was scarcely likely to survive the massive gangrene and bilateral amputations that her 'saddle' embolus would have caused. There were, moreover, other factors that made her death inevitable.

In performing embolectomy, the surgeon is merely ensuring that a sound limb awaits those who will recover from the dangerous illness which has caused embolism; in this way the small band of survivors can be spared the final handicap of an amputation.

The embolectomies referred to above were performed variously by Professor A. G. R. Lowdon, E. G. Hardy, L. B. Fleming and the author.

I am indebted to D. P. Hammersley for the drawings.

\section{REFERENCES}

I. CRAWFORD, E. S., and DE BAKEY, M. E. (1956), Surgery, 40, 737.

2. DYE, W. S., OLWIN, J., JAVID, H., and JULIAN, O. C. (1955), Arch. Surg., 70, 715.

3. HARDY, E. G., and TIBBS, D. J. (1960), Brit. med. F., awaiting publication.

4. JACOBS, A. L (I950), 'Arterial Embolism in the Limbs. Edinburgh and London: Livingstone.

5. LERMAN, J., MILLER, F. R., and LUND, C. C. (1930)? F. Amer. med. Ass., 94, 1128.

6. OLWIN, J. H., DYE, W. S., and JUlian, O. C. (1953), Arch. Surg., 66, 480 .

7. SHAW, R. S. (1956), Surg. Gynaec. \& Obstet., 103, 279.

\section{NOTICE OF SPECIAL INTEREST TO SUBSCRIBERS:}

\author{
'WHY NOT HAVE YOUR COPIES OF THIS \\ JOURNAL BOUND INTO YEARLY VOLUMES?'
}

You can have your twelve monthly issues fully bound in dark green pin head cloth. lettered in gile on spine with name of Journal, Volume Number and year, complete with index at front, for 22s. 6d. post free. A limited number of out of print journals are available to bind into volumes and make your library complete. Price on application siving details of issues required to complete back volumes.

THE FELLOWSHIP OF POSTGRADUATE MEDICINE 60 PORTLAND PLACE, LONDON, W.I
WHY NOT HAVE YOUR JOURNALS BOUND? 